\title{
LA LECTURA EN VOZ ALTA EN LA FORMACIÓN INICIAL DE LOS MAESTROS DE EDUCACIÓN INFANTIL DE LA UNIVERSIDAD DE CÁDIZ
}

\author{
Using Reading Alouds in Early Childhood Teacher \\ Preparation Programs at University of Cádiz \\ LA LECTURE À HAUTE VOIX DANS LA FORMATION INITIALE DES INSTITUTEURS \\ Á L'Université de CADiX
}

\author{
Ester Trigo-Ibáñez \\ Ph. D. en Lengua Española y \\ Enseñanza de Lenguas, Universidad de \\ Cádiz, España. \\ Profesora contratada doctora, \\ Departamento de Didáctica de la \\ Lengua y la Literatura, Universidad de \\ Cádiz, España. \\ ester.trigo@uca.es \\ http://orcid. \\ org/0000-0003-3035-4398

\section{Paula Rivera-Jurado} \\ Ph. D. en Ciencias Sociales y \\ Jurídicas, Universidad de Cádiz, \\ España. \\ Profesora sustituta interina, \\ Departamento de Didáctica de la \\ Lengua y la Literatura, Universidad \\ de Cádiz, España. \\ paula.rivera@uca.es \\ https://orcid. \\ org/0000-0002-4191-1367
}

\section{Susana Sánchez-Rodríguez}

Ph. D. en Didáctica de la Lengua.

Profesora contratada doctora,

Universidad de Cádiz, España.

susana.sanchez@uca.es

https://orcid.

org/0000-0003-3907-3795

\begin{abstract}
RESUMEN
El objetivo de esta investigación fue valorar la utilidad de una secuencia didáctica para mejorar la competencia en lectura literaria en voz alta de maestros de Educación Infantil en formación de la Universidad de Cádiz. En un marco de investigación-acción, se realizó un análisis de contenido de los datos generados en dicha implementación: listado de obras seleccionadas para la lectura, grabaciones en vídeo de las lecturas en voz alta, rúbricas para la coevaluación, foros de e-autoevaluación registrados en la plataforma del curso y un grupo focal de discusión. Los resultados mostraron que la implementación de la secuencia fue efectiva para permitir que el alumnado avanzara en su competencia lectora en voz alta. Además, posibilitó la compilación de un corpus de obras idóneas para la lectura en voz alta. Sin embargo, se detectaron carencias en relación con la selección de las obras y dificultades en la realización de la lectura para lograr la comprensión por parte del público. Se constata también la necesidad de integrar la formación lingüística y literaria en los programas de formación de maestros y el interés de utilizar la evaluación formativa para fomentar un aprendizaje reflexivo.
\end{abstract}

Palabras clave: formación inicial de maestros; educación infantil; lectura literaria; lectura en voz alta; literatura infantil.

\section{Abstract}

The objective of this study was to evaluate the effectivenes of a didactic sequence in improving literary reading out loud competence, as reflective formation skill of Early Childhood preservice teachers at University of Cádiz. Within an action-research study, a content analysis of the data collected during the pedagogical sequence was carried out. These data included a list of books selected for reading, video-recordings of the reading-alouds, peer-assessment rubrics, forums for e-self-evaluation launched through the course platform, and a focus group. The results show that the implementation of the sequence was effective in helping students improve 
Trabajo realizado en el marco del proyecto de la convocatoria ACTÚA de la Universidad de Cádiz, "La competencia en comunicación oral en la formación del profesorado de infantil, primaria y secundaria. Diagnóstico y acciones formativas coordinadas a través de las asignaturas de lengua materna" (sol-2018001 12864-tra). their reading aloud competence. In addition, it enabled the compilation of a corpus of works suitable for reading aloud. Nonetheless, some deficiencies were detected in relation to the selection of literary pieces, and some difficulties in the execution of the read-alouds were detected, all of which impeded understanding from the public. In conclusion, the need to integrate linguistic and literary training in the Early Childhood programs is evident and so is the interest in using formative assessment to foster reflective learning.

Keywords: teacher preparation; early childhood education; reading aloud; children's literature; literary reading.

\section{RÉSUMÉ}

L'objectif de cet travail de recherche a été d'évaluer l'implémentation d'une séquence didactique pour améliorer les compétences de lecture littéraire à voix haute des instituteurs en formation à l'Université de Cadix. Dans le cadre d'une recherche-action, on a mené une analyse de contenu des données générées à partir de cette implémentation : liste de lecture des œuvres sélectionnées, enregistrements vidéo de lectures à voix haute, grille pour la co-évaluation, forums de e-évaluation enregistrés sur la plate-forme du cours et groupe focalisé de discussion. Les résultats ont montré que l'implémentation de la séquence a été efficace pour aider les élèves à améliorer leurs compétences à lire à haute voix. En outre, cette implémentation a permis de compiler un corpus d'ouvres pertinentes pour la lecture à voix haute. Cependant, l'on a détecté certains manques quant à la sélection et des difficultés pour en réaliser la lecture afin d'obtenir une compréhension idoine de la part du public. En plus, on constate le besoin d'intégrer la formation linguistique et littéraire dans les programmes de formation des instituteurs ainsi que la pertinence de l'évaluation formative pour susciter un apprentissage réflexif.

Mots-clés : formation des instituteurs ; éducation prescolaire ; lecture littéraire ; lecture à haute voix ; littérature d'enfance. 


\section{Introducción}

En el campo de la didáctica de la lengua y la literatura (DLL) es habitual establecer límites entre oralidad y escritura. Los materiales didácticos separan las propuestas para lengua oral y escrita, e incluso en la formación de maestros se ofrecen materias específicas para cada dimensión, tanto en el ámbito lingüístico como literario. Sin embargo, la oralidad y la escritura se relacionan de forma compleja (Ferreiro, 2002) y estas relaciones son muy relevantes en el desarrollo de la alfabetización en la infancia (Sánchez Rodríguez, 2014). Por ello, este trabajo aborda un espacio de intersección entre oralidad y escritura: la competencia en lectura en voz alta de textos literarios en la formación inicial de maestros de Educación Infantil.

No conocemos investigaciones sobre las capacidades del alumnado de los grados de maestro para leer en voz alta; además, escasean los ejemplos de ecuencias didácticas destinadas a niveles académicos superiores que aborden esta cuestión (Grau y Vilá, 2005) y, aún más, los específicamente dedicados a la literatura (Morón y Martínez, 2013). Por ello, nos planteamos la necesidad de investigar en el desarrollo de esta competencia profesional.

Nuestro objetivo principal es valorar la utilidad de una secuencia didáctica dirigida a la mejora de la competencia profesional de lectura literaria en voz alta. Nos centramos en la narrativa, por ser el género más presente en la oferta editorial (Sánchez Hita y Romero, 2018) y más cercano a la experiencia lectora de nuestros estudiantes. Para cumplir este objetivo, nos planteamos las siguientes preguntas de investigación: ¿qué obras literarias son las más idóneas para ser leídas en voz alta según el criterio de los futuros maestros? ¿Cuáles son los principales logros y carencias presentados por los futuros maestros al realizar la lectura en voz alta?

\section{Marco teórico}

Leer en voz alta significa leer para otros, no simplemente ante otros. Un único lector proyecta el discurso escrito a través de la oralidad, permitiendo a otros acceder a dicho discurso, lo que le exige tomar en cuenta tanto lo que lee como para quién lee (Dolz y Schneuwly, 2016; Palou y Bosch, 2005). Este tipo de lectura implica favorecer y lograr la comprensión total del texto escrito por parte del lector, mediante la calidad de su transmisión oral. Se trata, pues, de una lectura exigente, que combina rasgos de comunicación escrita y oral.

\section{La lectura en voz alta en la escuela: beneficios y exigencias}

La lectura en voz alta es sin duda una importante competencia profesional del docente, ligada a los procesos de alfabetización, el fomento lector y la educación literaria de los escolares, quienes adquieren progresivamente la capacidad de leer textos de todo tipo de forma autónoma y eficaz. Durante este proceso son asistidos por mediadores que leen en voz alta para ellos: sus familiares, narradores profesionales, bibliotecarios y, por supuesto, sus maestros (Romero y Álvarez, 2018; Romero y Trigo, 2014). Esta mediación permite acceder a la naturaleza estética, discursiva, sintáctica, léxica y gráfica de la lengua escrita, poniendo de manifiesto la relevancia de la actividad de los adultos como lectores expertos para quienes están aprendiendo (New, 2001), y cumple un importante papel no solo en el proceso de alfabetización inicial, sino también a lo largo de la escolaridad (Fandiño et al., 2013).

Centrándonos en el docente de Educación Infantil, en diversos trabajos se exponen los beneficios a largo plazo de la lectura en voz alta dirigida a niños menores de 6 años para el desarrollo lingüístico, la alfabetización o el hábito lector (Goikoetxea y Martínez, 2015; Massaro, 2017; Santana et al., 2017). Por otro lado, las experiencias de lectura en voz alta en la primera infancia proporcionan una vivencia literaria y emocional que contribuye a construir lectores literarios (Calonje, 2007; Mata, 2004; Munita y Riquelme, 2013), facilita el acceso a un habla descontextualizada del aquí y el ahora en torno a la lectura (Duursma et al., 2008) y, además, habitúa a los niños a elaborar colectivamente significados (Mata, 2016) que pueden ampliarse por 
medio de experiencias de lectura dialógica (Romero y Trigo, 2014; Soler, 2003).

Así, es interesante que el docente comparta textos de diversos usos con los niños (Tolchinsky, 1990), aunque destacamos el valor añadido del texto literario, puesto que conjuga los beneficios más asociados al desarrollo lingüístico, con los que implica la experiencia literaria (Munita y Riquelme, 2013). Sin embargo, a pesar de que existen propuestas didácticas dirigidas a la práctica de la lectura expresiva en el aula (Romero, 2011), esta requiere de un cuidado en su planteamiento didáctico, que no siempre se respeta y puede dar lugar a prácticas que desvirtúan su valor (Cassany, 2007).

\section{La formación de maestros para la lectura de textos literarios en voz alta}

La lectura en voz alta de textos literarios para niños de entre 0 y 6 años es, si se hace adecuadamente, una actividad con alto potencial de aprendizaje. No obstante, el hecho de encontrarse en una intersección entre, por una parte, lo oral y lo escrito y, por otra, lo lingüístico y lo literario, puede provocar que permanezca en un nivel poco visible en formación inicial. En este sentido, es el cometido de las materias vinculadas a la DLL ofrecer, de manera explícita, esta formación a los futuros maestros, desde tres ámbitos de competencia del docente de Educación Infantil: literatura infantil, pues debe saber seleccionar el libro y valorar su potencial literario; competencia en comunicación oral, ya que debe saber realizar la lectura oral para los otros, y competencia en comunicación escrita, puesto que exige una comprensión previa y profunda del texto escrito y una conciencia de mediación para el aprendizaje de esta dimensión comunicativa.

Por ello, y con la voluntad de superar la fragmentación de la formación de maestros, en tanto responsables del desarrollo de la competencia comunicativa y literaria de los niños de Educación Infantil que algunos estudios han señalado (Granado, 2013; Santamarina y Núñez, 2018), resulta necesario darle a la lectura en voz alta un espacio propio y coordinado entre asignaturas. Se evita así que una actividad tan esencial sea resuelta de forma simple por maestros noveles desde sus experiencias lectoras en la infancia, no siempre positivas o bien ya no adecuadas para compartir con niños de otras generaciones (Dueñas et al., 2014). Por el contrario, la formación debe superar la experiencia lectora de cada estudiante (Juárez, 2019; Granado y Puig, 2015; Munita, 2013; Parrado et al., 2018; Romero y Trigo, 2018), garantizar que los futuros maestros dispongan de herramientas que posibiliten su adecuada competencia en lectura en voz alta en su desempeño profesional y, además, que se potencie su formación en literatura infantil, tan esencial como insuficientemente considerada en la formación inicial (Ibarra y Ballester, 2013; Moreno y Sánchez Vera, 2000).

Algunos manuales para la formación docente en DLL ofrecen, desde el ámbito lingüístico o literario, algunas pautas para la actuación (Colomer y Durán, 2000; Díaz-Plaja, 2016), que nos invitan a poner en práctica la lectura en voz alta dándole el tiempo que merece y a evaluarla desde una perspectiva formativa (Dolz y Schneuwly, 2016; Moreno y Sánchez Vera, 2006; Palou y Bosch, 2005).

\section{Método}

Este trabajo, enmarcado en la investigación-acción, se inserta dentro del paradigma cualitativo y se aborda desde un enfoque etnográfico y reflexivo (Sáez, 2017) que ahonda en la realidad del aula - desde la voz de los discentes y la mediación docente- Se desarrolla en el ámbito de investigación en DLL, que tiene como cometido comprender la actividad de aula para "aportar nuevos conocimientos y con ello innovaciones que incidan en la mejora de la práctica” (Mendoza, 2011, p. 32).

La población objeto de estudio se compone de los 215 estudiantes matriculados en la asignatura "Didáctica para el Desarrollo de las Habilidades Comunicativas Orales" $(N=215)$ de la Facultad de Ciencias de la Educación de la Universidad de Cádiz en el curso 2018-2019. Estos 215 estudiantes se dividen en 
tres clases: A, B y C. De ellos, 195 (90,70 \%) son mujeres y 20 (9,30 \%) son hombres. Dado que los estudiantes afrontan la experiencia divididos en microgrupos, se ha considerado que la muestra, de carácter censal, coincide con el número de grupos formados $(n=53)$. De este modo, en las clases A y $\mathrm{B}$ registramos 18 microgrupos respectivamente, $\mathrm{y}$ en la C, 17.

Para la obtención de la información, se diseñó una secuencia didáctica cuya implementación generó datos audiovisuales, orales y escritos. Estos datos fueron concretamente: el listado de obras seleccionadas para su lectura (81), grabaciones en vídeo de las lecturas en voz alta (53), rúbricas para la coevaluación (53), foros de e-autoevaluación registrados en la plataforma del curso (3) y un grupo focal de discusión.

La información recabada en la presente investigación se enmarca en el proyecto "La competencia en comunicación oral en la formación del profesorado de infantil, primaria y secundaria. Diagnóstico y acciones formativas coordinadas a través de las asignaturas de lengua materna”. En este marco, se obtuvieron los consentimientos informados de cada participante y se siguieron las normas éticas en cuanto a manejo y protección de datos se refiere.

Para el análisis de esta información se recurrió al análisis de contenido (Porta y Silva, 2003), en función de las diversas fuentes de información: así, se estableció un corpus de obras seleccionadas por los estudiantes (vid. Anexo 1) y se codificó el discurso que estos generaron en los foros de e-autoevaluación, coevaluación y el grupo focal, en virtud de los distintos ámbitos de interés de la experiencia: la selección de las lecturas, los aprendizajes logrados, las dificultades encontradas. ${ }^{1}$ Desde el análisis de dicha información y teniendo en cuenta

1 La codificación de los testimonios indica el modo de obtención (e-autoevaluación-EA, coevaluación-CO, grupo focal-GF), el ámbito de interés (selección-S, logros-L, dificultades-D) y los informantes (número de grupo y grupo-clase). Así, el código EA/L/G2B corresponde a la e-autoevaluación, ámbito logro, realizada por el grupo número 2 de la clase $\mathrm{B}$. la heteroevaluación efectuada por el profesorado, se generó el informe de resultados.

\section{La secuencia didáctica}

Para el diseño e implementación de la secuencia didáctica se tuvo en cuenta la trayectoria formativa en DLL para el grado en Educación Infantil de la Universidad de Cádiz (vid. Tabla 1).

Tabla 1 Itinerario específico en didáctica de la lengua y la literatura en la Universidad de Cádiz

\begin{tabular}{clc}
\hline Curso & \multicolumn{1}{c}{ Asignaturas específicas } & $\begin{array}{c}\text { Número de } \\
\text { créditos }\end{array}$ \\
\hline $2 .^{\circ}$ & $\begin{array}{l}\text { Didáctica para el Desarrollo de las } \\
\text { Habilidades Comunicativas Orales }\end{array}$ & 6 \\
$3 .{ }^{\circ}$ & $\begin{array}{l}\text { Didáctica para el Desarrollo de las } \\
\text { Habilidades Comunicativas Escritas }\end{array}$ & 6 \\
$4 .{ }^{0}$ & $\begin{array}{l}\text { Literatura Infantil y Fomento de la } \\
\text { Lectura }\end{array}$ & 6 \\
\hline
\end{tabular}

Se decidió intervenir en la primera asignatura del ámbito de DLL cursada por el alumnado del grado, donde se evidenció que existían importantes ejes de mejora, y se acordó que la evaluación formativa y compartida (López-Pastor y Pérez-Pueyo, 2017) sería clave para el diseño de la secuencia didáctica, que se organizó en seis fases:

Fase I. El andamiaje. Dada la escasa formación literaria de los estudiantes, se les proporcionaron recursos para acercarse a los libros infantiles: webs de instituciones que promueven la lectura (fundaciones, bibliotecas, escuelas...); blogs de docentes especializados en la formación lectora y literaria; webs de librerías; enlaces a diversas editoriales especializadas en literatura infantil, etc. Se establecieron pautas para seleccionar libros apropiados para educación infantil, focalizando en aspectos como la adecuación al destinatario, el uso de ilustraciones, la extensión y, sobre todo, la calidad literaria. Partiendo de las lecturas de Palou y Bosch (2005) y Montero (2012), se reflexionó sobre la práctica de la lectura en voz alta y se instó al alumnado a seleccionar una obra literaria de género narrativo para leerla ante el grupo la semana siguiente. 
Fase II. La lectura del cuento: una práctica de coevaluación. Antes de la lectura, se proporcionó al alumnado una rúbrica elaborada desde Moreno y Sánchez Vera (2006), con la que debía evaluar variables paralingüísticas y no verbales (vid. Anexo 2). Aclarados los aspectos evaluables, se procedió a la lectura grupal: los estudiantes debían organizar la narración en fragmentos, de manera que todos pudieran leer. Antes debían justificar su elección. Mientras realizaban la práctica, la docente fue grabando en vídeo, para posibilitar una reflexión posterior y facilitar el proceso de autoevaluación y heteroevaluación (Santos Guerra, 1993).

Fase III. La autoevaluación. Tras la lectura, se habilitó un foro en la plataforma Moodle de la asignatura, para que el alumnado plasmara su e-autoevaluación y evidenciara sus principales logros y dificultades.

Fase IV. En busca de referentes teóricos. Una vez terminada la práctica, se procedió a ampliar la formación del alumnado sobre los conceptos comunicación oral y comunicación no verbal (Amar, 2014; Palou y Bosch, 2005). Tras esto, se les instó a confeccionar una nueva rúbrica (vid. Anexo 3), para evaluar, en una segunda sesión, la lectura para los demás.

Fase v. Una nueva lectura coevaluada. Tras el recorrido formativo-reflexivo, se procedió a la segunda lectura en voz alta. Igual que en la ocasión anterior, el alumnado realizó la correspondiente coevaluación y la docente recogió testimonio audiovisual para incorporarlo al proceso de heteroevaluación. En esta ocasión, el alumnado podía cambiar la obra seleccionada o, incluso habiéndola mantenido, proponer otros títulos que consideraba adecuados.

Fase VI. Reflexionando sobre la experiencia. Para finalizar, se requirió una nueva autoevaluación y, a partir de los aspectos más llamativos, se organizó un grupo focal, para recoger la voz del alumnado con respecto a la experiencia formativa.

\section{Resultados}

Los resultados obtenidos se han organizado para dar respuesta a las preguntas de la investigación. Por un lado, se exponen los principales hallazgos a partir del corpus de lecturas generado por los informantes. Por otro lado, se muestran los resultados relacionados con los principales logros y carencias encontrados por los participantes al afrontar una lectura en voz alta.

\section{Las obras literarias más idóneas}

En total, entre los títulos que fueron leídos y aquellos que se propusieron y que, por tanto, fue interesante recoger, se identificaron 81 obras (vid. Anexo 1). Según la selección obtenida, parece existir un conocimiento difuso en cuanto a la diferencia entre libros de no ficción (Gill, 2009) y libros de literatura infantil. Aunque la mayor parte de los títulos se incluye en esta segunda categoría ( $A$ qué sabe la luna, Elmer, El pez Arcoíris, La pequeña oruga glotona, entre otros), también se localizan otros más próximos a la literatura instrumentalizada (Cervera, 1989), por su intención más didáctica que literaria: De qué están hechas las niñas flamencas, En la selva, El monstruo de los colores o Las cuatro estaciones en un día. Así, parece extendida la creencia, entre el alumnado, de que cualquier libro sería apropiado para leerse en voz alta, independientemente de su valor literario. Sin embargo, aunque no pongamos en cuestión la calidad, necesidad y pertinencia de utilizar libros de no ficción en el aula (Young et al., 2007), el propósito de la secuencia didáctica se acotaba a la lectura de textos literarios:

\footnotetext{
Hemos decidido elegir este libro porque creemos que no es un cuento muy extenso para que los niños no pierdan la atención al leerlo. Además, vemos muy importante que el cuento trata sobre la educación emocional y los niños pueden expresar sus sentimientos (EA/S/G5A).
}

Además, este corpus refleja cuáles son los criterios en los que los estudiantes se apoyan para respaldar la elección la obra. Así, aparecen razones como:

1. El valor lúdico: "Este libro es recomendable leerlo en voz alta, porque fomenta que los niños se diviertan" (EA/S/G2C). 
2. El componente estético: "Hemos decidido elegir dicho libro porque creemos que es un cuento cargado de ilustraciones llamativas para que los niños no pierdan la atención durante su lectura" (EA/S/G10C).

3. La conexión emocional con experiencias previas: "Lo hemos elegido porque lo teníamos en casa y era uno de nuestros cuentos favoritos de pequeñas" (EA/S/G9A).

4. El utilitarismo: "Hemos elegido este libro porque es breve, tiene un lenguaje sencillo, tiene muchas ilustraciones e iluminación y le enseña las fases de la luna a los pequeños" (EA/S/G9B).

Estas razones pueden aparecer independientemente o combinadas. Así, quienes eligen según el utilitarismo, no ligan este criterio con otros para apoyar su elección, pues lo estiman suficientemente potente:

Hemos elegido este libro porque nos parece una buena opción para tratar la diversidad en educación infantil y para acabar con los estereotipos de géneros (EA/S/G7A).

Hemos considerado que es idóneo este libro para la lectura en voz alta, porque fomenta la adquisición de rutinas cotidianas, al contener un tema transversal como es la higiene y [el] cuidado personal en este caso (EA/S/G11C).

Se registran, asimismo, títulos seleccionados bien por la oportunidad que ofrecen de transmitir valores - El monstruo de los colores, La cigarra y la hormiga o Fréderik - o bien por la extensión y la temática - Los tres cerditos, En la selva o El pollito Pito-:

Hemos elegido este cuento porque se trata de una narración tradicional que cuenta con ilustraciones que representan muy bien la historia. Es un cuento corto, en el que aparecen animales, aspectos que atraen la atención de los niños (EA/S/G10B).

Sin embargo, quienes recurren al criterio lúdico o estético, suelen asociarlo con sus experiencias de lectura como disfrute (Lomas, 2003; Romero et al., 2015):
Consideramos que este libro es el más adecuado, porque es muy divertido, muy interactivo. También por ser uno de los libros que más nos leían cuando éramos pequeñas (EA/S/G11A).

De esta forma, se recogen títulos desde sus vivencias como lectores infantiles -Este pijama está loco o El hada acatarrada, obras editadas en la década de los noventa-, y desde su proyección como docentes mediadores, títulos más actuales: Veo-veo... Un ratón o La vaca que puso un huevo. Estos resultados concuerdan con investigaciones precedentes (Dueñas et al., 2014; Granado y Puig, 2014; Munita, 2019), que muestran la influencia de las experiencias lectoras del profesorado en formación al seleccionar las obras para el aula.

Unido a esto, hay determinados títulos que se repiten:

- De los clásicos infantiles: Los tres cerditos, Caperucita roja, La ratita presumida, El zorro y el caballo o El gato con botas. Sobre ellos, el acento se vuelve a poner en el mensaje que transmiten o en el hecho de que el cuento nos transporta "a paraísos inventados, cercanos a nuestra infancia, para arribar a sueños y a recuerdos de imágenes familiares que nos han acompañado en diversos momentos vitales" (Romero, 2016, p. 13):

De esta historia sacamos la conclusión de que siempre hay que decir la verdad y esto supondrá un aprendizaje para los niños (EA/S/G7B).

Este cuento me lo leía mi padre antes de dormir y para mí tiene un valor muy especial. Creo que hay que transmitir esos sentimientos a los más pequeños, porque los cuentos siempre te acompañarán (EA/S/G16C).

- De literatura infantil de reciente edición: Elmer, Las jirafas no pueden bailar, El pez Arcoiris o A qué sabe la luna, son los títulos en los que más se insiste. Algunas de estas obras son reconocidas por el Observatorio de la Lectura y el Libro (España, Ministerio de Educación, Cultura y Deporte y Observatorio 
de la Lectura y el Libro, 2018) entre las más vendidas para los primeros lectores o prelectores, de 0 a 6 años.

A modo de resumen, la Figura 1 -realizada con la aplicación Tag Cloud - ofrece una nube de palabras a partir de los testimonios aportados por los informantes acerca de las razones que les han llevado a seleccionar las obras. En ella, el tamaño de las palabras mostradas es directamente proporcional al número de evocaciones por parte de los participantes. Lo primero que destaca es la palabra cuento, referida al género literario que los informantes consideran más idóneo para ser leído en voz alta. En cuanto a las razones, destacamos un primer acercamiento a la literatura con valor utilitarista, manifiesto en las palabras: fomenta, aprendizaje, enseña, educación, estereotipos, diversidad..., frente a otras razones más relacionadas con la educación literaria y la mediación lectora: ilustraciones, personajes, voz, lenguaje... Los maestros, en su segundo año de formación - como recoge la Tabla 1 -, no han cursado aún la asignatura enfocada a la adquisición de la competencia para incorporar el criterio estético-artístico al realizar una buena selección de obras literarias que puedan ser leídas en el aula.

\section{Logros y carencias encontrados}

Se han organizado los datos obtenidos en función de los principales logros y las dificultades encontradas por los participantes - estudiantes (auto y coevaluación) y docentes (heteroevaluación) - durante el proceso de lectura en voz alta, en las distintas fases de la secuencia didáctica.

En cuanto a los aspectos positivos, se consignan referencias a la adecuada selección de la obra para ser leída en voz alta y al acto de lectura en sí. Atendiendo a la selección, los estudiantes destacan el hecho de haber llevado a cabo una correcta elección, en la que se tuvieron en cuenta los aspectos estudiados en clase:

[...] el libro ha sido apropiado a la edad, ya que es original y que llama la atención a niños de estas edades $(\mathrm{EA} / \mathrm{L} / \mathrm{G} 8 \mathrm{~B})$.

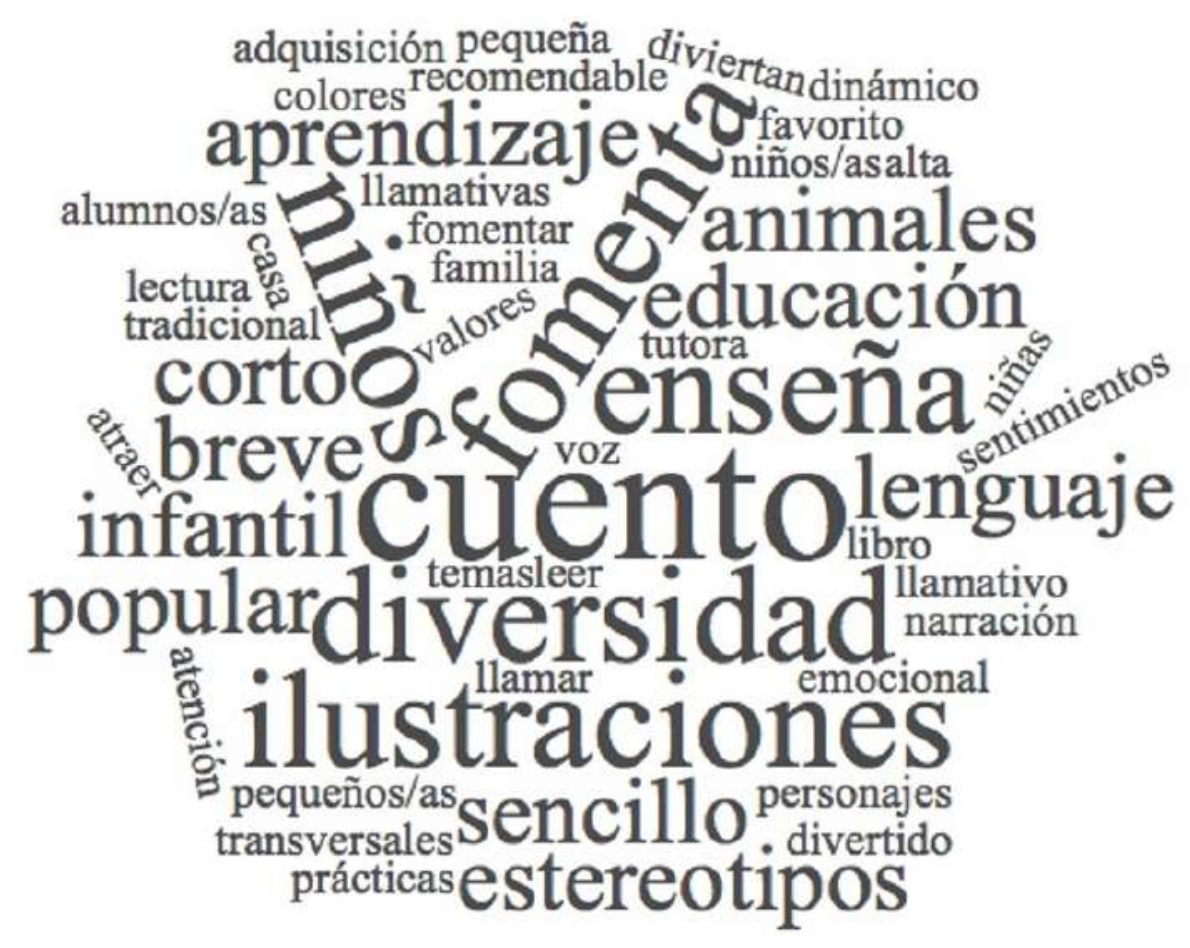

Figura 1 Nube de palabras. Principales razones de los futuros maestros para la selección de las obras. 
Nos parece apropiada la elección del cuento, ya que no tiene ningún fin pedagógico, sino el simple hecho de entretener y divertir a los niños. Además, las ilustraciones son muy coloridas, lo que puede llamar la atención de los niños (GF/S/G12A).

Sin embargo, aunque en el proceso de andamiaje se había subrayado esto, hubo grupos que consideraron la finalidad pedagógica el principal aspecto positivo de la lectura; por ejemplo:

[...] son cuentos buenos, que enseñan valores (CO/S/ G16B).

[...] los cuentos nos han gustado porque fomentan capacidades como el compañerismo, la solidaridad, la amistad, la autonomía... (CO/S/G5A).

Atendiendo al acto de lectura, los estudiantes ponen en valor aspectos referidos a la entonación y la modulación, el ritmo y la gesticulación. Además, añaden apreciaciones sobre el disfrute que les había proporcionado la experiencia:

[...] a pesar de los nervios, la entonación y modulación fue buena. Se nos entendía cuando hablábamos y utilizábamos gestos mirando a los compañeros. Además, enseñamos en todo momento las imágenes del libro (EA/L/G16C).

Muy buena entonación a la hora de narrar el relato entero $(\mathrm{CO} / \mathrm{L} / \mathrm{G} 2 \mathrm{~B})$.

Han empleado regularmente pausas y silencios, que nos ha ayudado a interpretar mejor el cuento (CO/L/ G14A).

[...] la rúbrica ha tenido gran importancia, ya que nos ha servido para fijarnos en todos los aspectos que debemos tener en cuenta a la hora de leer en voz alta (GF/S/G9C).

[...] ha sido muy buena práctica, porque hemos aprendido cosas que van a ser muy significativas en el día de mañana $(\mathrm{GF} / \mathrm{S} / \mathrm{G} 7 \mathrm{~B})$.

Además, destaca el hecho de haber potenciado un proceso de reflexión sobre la práctica y sobre la evaluación en los maestros en formación, vital para toda persona que ejerza la profesión docente. Esto ha permitido hacer consciente al alumnado de la importancia de leer para los demás y de los elementos que deben activarse en una lectura en voz alta:
[...] el trabajo de la propuesta de rúbrica nos ha ayudado a saber qué es lo que necesitábamos para contar mejor el cuento: hemos enseñado el libro, intentado mirar a toda la clase, hablar alto, claro, utilizar onomatopeyas, gesticular y diferenciar, con la voz, cada uno de los personajes (GF/L/G13A).

En consonancia con la idea, reflexionar sobre los aspectos prosódicos, paralingüísticos y no verbales ligados a la lectura en voz alta para enfrentar la segunda lectura supuso, desde el punto de vista de la heteroevaluación, un gran avance que la coevaluación corrobora. Se constata que los grupos seleccionaron obras más adecuadas, fueron más conscientes de los aspectos que debían controlar para desarrollar una lectura de calidad y más precisos a la hora de valorar las lecturas de sus compañeros. Además, dotaron de mayor entidad a sus lecturas, incorporando fórmulas de inicio y cierre. Recogemos algunas de las valoraciones del alumnado al respecto:

\section{Nos gustó mucho este cuento y era muy entretenido, nos hizo reír; por lo tanto, creemos que es buena refe- rencia para utilizarlo en la etapa de Infantil (CO/L/ G7C). \\ La buena entonación ha hecho que los personajes cobren vida [...]. Utilizan una pregunta al inicio del cuento como gancho bastante acertada (CO/L/ G14B).}

En suma, los estudiantes destacan muy positivamente el hecho de haber elaborado la rúbrica desde el proceso formativo, la seguridad adquirida para leer en voz alta utilizando conscientemente recursos expresivos, la aplicabilidad de la lectura en un contexto real -o profesional-, o el conocimiento de obras y autores de literatura infantil.

En cuanto a las dificultades, se han agrupado también en torno a la elección de la obra y el acto de lectura en sí. En primer lugar, la elección de la obra, como ya hemos indicado, supuso un reto para el alumnado, que partía de una idea utilitarista de la literatura (Cervera, 1989). Al respecto, los estudiantes aportan razones de tres tipos: la no adecuación a los receptores potenciales - niños de entre 0 y 6 años-, debido a la complejidad o el enfoque de la 
temática; la excesiva duración del acto lector y el hecho de haber seleccionado la obra por su finalidad pedagógica y no por su calidad literaria.

[...] no contamos con que era un cuento extenso y se despistaron muchos los oyentes y dejaron de prestar atención. La próxima vez cogeremos un cuento más corto y apropiado para el público infantil (EA/D/G9C).

No leímos los diálogos lo suficientemente despacio, por lo que un niño no habría podido interesarse en el cuento. Además, no empleamos gestos que acompañaran dicha lectura (EA/D/G10A).

En segundo lugar, sobre el acto de lectura en sí, demostró el bajo grado de conciencia por parte del alumnado de los recursos paralingüísticos y no verbales que contribuyen a dar calidad a la lectura en voz alta, así como déficits en modulación de la voz, ritmo de la lectura, gestualidad y contacto visual (Amar, 2014; Palou y Bosch, 2005), aspectos que fueron constatados también en la heteroevaluación.

[...] a pesar de los ensayos, al saber que estábamos siendo grabados nos sentimos nerviosos. Esto hizo que no moduláramos la voz como queríamos (EA/D/G1C).

El cuento tiene grandes posibilidades para utilizar la voz, pero el grupo no supo aprovecharlo (CO/D/ G3A).

No emplearon gestos faciales ni de otro tipo para enfatizar lo que se estaba contando en la narración (CO/D/G10C).

Finalmente, nos detenemos en un aspecto que emergió de los datos obtenidos y afecta tanto a la selección de las obras como a la realización de la lectura: el componente actitudinal de los estudiantes a la hora de enfrentarse a la actividad, que, a la vista de los hallazgos, resultó ambivalente, puesto que se puso de manifiesto un claro entusiasmo hacia la experiencia, basado, por un lado, en el disfrute de los textos y, por otro, en la utilidad para su futuro desempeño profesional. Pero también se constató poco ensayo y escasa consulta de los recursos ofrecidos para la selección de las obras (Dueñas et al., 2014; Munita, 2019).

Tuvimos poco tiempo para ensayar, así que nuestra puesta en escena no salió como habíamos pensado (EA/D/ G6A).
Pensamos en los libros que nos habían gustado de pequeñas, sin más. No consultamos todos los enlaces que nos aportaron las profesoras... A lo mejor habríamos encontrado un cuento más adecuado (GF/D/G12C).

En resumen, los resultados, obtenidos de los distintos agentesinvolucrados en el proceso de evaluación, coinciden al señalar que los estudiantes han avanzado en su competencia profesional en lectura en voz alta, de forma que las dificultades detectadas en la fase II de la secuencia didáctica lograron corregirse en la fase $\mathrm{v}$, tras los procesos reflexivos planteados y con la perspectiva de poder repetir la experiencia.

En este sentido, ha sido vital la reflexión sobre cómo leer en voz alta para entregar un texto escrito a un público que lo escucha (Mata, 2004, 2016; Morón y Martínez, 2012). Para ello, los estudiantes se han enfrentado a la comprensión profunda del texto como paso previo a compartirlo oralmente, considerando el nivel de condensación narrativa de las distintas obras (Granado, 2013; Grau y Vilá, 2005; Llamazares y Alonso-Cortés, 2016). Han adquirido también conciencia sobre su desempeño oral y lo han mejorado en aspectos prosódicos, paralingüísticos y de comunicación no verbal, que condicionan la calidad de la lectura en voz alta en la escuela infantil y dan cuenta de su mejora en el control de la densidad de la narración al compartirla (Amar, 2014; Palou y Bosch, 2015). Además, el alumnado ha experimentado la necesidad de saber elegir qué leer a un público de niños menores de 6 años desde criterios docentes (Díaz-Plaja, 2016; Munita, 2013).

Así, los estudiantes, desde sus diferentes trayectorias académicas y de vida, han reconocido la necesidad de ser lectores competentes de obras considerando el público infantil; han experimentado el valor estético y lúdico de los títulos seleccionados frente al didactismo (es decir, seleccionar los textos solo con el fin de enseñar algo); han comprobado el interés de aportar ediciones actuales; se han familiarizado con las ilustraciones de calidad y han sabido jugar con recursos, como las estructuras repetitivas o que den protagonismo a 
la sonoridad y al ritmo: “QQué patraña qué mentira, ese huevo es de gallina!", elementos que pueden ayudar a que el público infantil tome un papel activo en la escucha del texto, al poder anticiparse - $\mathrm{o}$ incluso cantar - enunciados predecibles: "Lalaralarita, barro mi casita" (Dueñas et al., 2014; Granado y Puig, 2014; Romero y Álvarez, 2018; Sánchez Hita y Romero, 2018).

\section{Discusión y conclusiones}

Para finalizar este trabajo, planteamos los siguientes ejes de reflexión: en primer lugar, este trabajo confirma la validez de incorporar secuencias didácticas en la educación superior, en particular para intervenir en el desarrollo de una competencia profesional compleja, que se encuentra en la intersección entre la competencia oral, escrita y literaria de los futuros docentes.

Con ello, se suma a otros estudios que presentan el valor de la secuencia didáctica para intervenir en la competencia en comunicación lingüística del alumnado (Campsy Vilà, 2003; Dolz y Schneuwly, 2016; Vilà, 2005) y aporta complejidad, al proporcionar avances no solo para la realización oral de la lectura literaria, sino también en la conciencia de la calidad de la mediación docente entre el texto escrito de carácter literario y los niños menores de 6 años.

Este nivel de conciencia sobre la gestión de la oralidad en el aula es un aspecto muy relevante para la mejora de la práctica educativa desde la Educación Infantil (Llamazares y Alonso-Cortés, 2016; Sánchez Rodríguez, 2008, 2016; Santamarina, 2016; Wells, 2001, 2015).

En segundo lugar, destacamos el valor de la evaluación formativa en el proceso de aprendizaje (Ribas, 2010): ha resultado muy positivo el hecho de involucrar al alumnado en su proceso de e-autoevaluación (Rodríguez et al., 2011) y de coevaluación (Gatfield, 1999; Ibarra et al., 2012), prácticas aún por explorar con mayor profundidad en la educación superior.

Nuestros hallazgos coinciden con los de la investigación realizada por Rodríguez et al. (2011), ya que la e-autoevaluación — a través del foro- ha favorecido la participación de los estudiantes, además de suponer un ejercicio de autorregulación y autorreflexión crítica sobre su grado de conocimiento — de obras literarias - y desarrollo de habilidades - para una adecuada lectura en voz alta-. El hecho de que las dificultades detectadas en la fase II de la secuencia didáctica lograran corregirse en la fase $\mathrm{v}$ corroboró nuestra intuición acerca del uso de la autorreflexión como mejora de los procesos de aprendizaje y coincide, además, con otras investigaciones precedentes, que si bien no están enmarcadas dentro de la oralidad, sí demuestran una mejora de la competencia lingüística y de la reflexión pedagógica de los futuros maestros a partir de procesos de autorreflexión (Jarpa, 2019; Plazaola et al., 2018; Yoon y Römer, 2020).

En tercer lugar, nuestro trabajo aporta nueva información respecto a los avances en la formación en competencias específicas para el ejercicio de la profesión docente. Se trata de una formación no lineal, ya que se construye en relación con creencias y representaciones sociales que los estudiantes manejan y que pueden ser incoherentes con los saberes que, desde el ámbito formativo, se busca que puedan construir.

Frente a trabajos que se han ocupado de estas cuestiones en lo que respecta a la lengua oral (Ballesteros y Palou, 2005; Santamarina, 2011), la lengua escrita (Birello y Gil, 2014; Pérez Peitx, 2016) o la educación literaria (Munita, 2013), este trabajo combina los tres ámbitos y contribuye así a informar sobre el proceso dinámico de construcción progresiva de las competencias profesionales.

Por ejemplo, si bien inicialmente los estudiantes no tenían clara la diferencia entre los libros de no ficción y la literatura infantil (Gill, 2009), entendimos esta circunstancia como una oportunidad de aprendizaje que enlaza con las otras materias lingüísticas del grado y que va a contribuir a cohesionar la formación literaria del futuro maestro (Trigo, 2016). Los resultados demuestran que ya desde la primera asignatura del itinerario lingüístico se ha logrado 
instar al alumnado a descubrir obras de literatura infantil, propiciando una postura crítica respecto a la selección de obras adecuadas, la formación de un amplio corpus de lecturas y la concienciación de valorar la lectura como disfrute, frente a la visión instrumentalizada (Dueñas et al., 2014; Granado y Puig, 2015; Munita, 2013).

Sin embargo, también encontramos algunas dificultades, pues durante su proceso formativo como futuros docentes, los estudiantes adquieren la idea de que la literatura, más allá de constituir un elemento necesario para forjar lectores, debe utilizarse como un instrumento para formar en valores. De hecho, una rápida revisión de los trabajos de fin de grado defendidos durante los últimos años en distintas universidades, pone de manifiesto cómo, desde la didáctica general, en ocasiones, se focaliza la mirada en la visión utilitarista de la literatura infantil (Ayuso, 2013; Chira, 2018; Vicario, 2019), mientras que desde la DLL se aboga por la formación de lectores hacia el disfrute del texto literario (Planella, 2015; Ruiz, 2019; Sánchez Fernández, 2014). Bajo estas premisas, resulta complejo que los estudiantes tengan claro cuál es el sentido de la literatura, cómo propiciar su disfrute compartido y el papel que esta debe desempeñar en la vida de los nuevos lectores. Nuevos trabajos podrán explorar de qué forma los futuros maestros construyen un conocimiento consolidado para su práctica desde postulados a veces contradictorios y cómo la lectura en voz alta debe afrontarse de distinta forma según sea la naturaleza del texto compartido.

En este sentido, y como cuarta conclusión, este estudio aporta, a la formación inicial de maestros, resultados que indican la validez de trabajar de manera coordinada entre asignaturas dentro del ámbito universitario (Bolarín y Moreno, 2015; Sánchez Jiménez y Galiano, 2019), ya que, en nuestro caso, se ha constatado un avance formativo en el alumnado, al contribuir a estructurar su formación en didáctica de la oralidad, didáctica de la escritura y en literatura infantil de una manera interrelacionada y significativa (Santamarina y Núñez, 2018). Esta competencia resultará trascendental en el desarrollo de su desempeño profesional como alfabetizadores y mediadores literarios.

Las voces y los testimonios de los estudiantes se han acompañado del diálogo entre las docentes, quienes, desde el proceso de heteroevaluación y como participantes de la investigación, han vivenciado los logros y aprendizajes del grupo. En este sentido, el trabajo en paralelo - o coordinación horizontaly el diseño de un itinerario específico de formación coherente -o coordinación vertical, reflejada en la Tabla 1- han enriquecido la visión de la experiencia y, desde el establecimiento de vasos comunicantes entre contenidos lingüísticos y literarios, han permitido fortalecer la competencia en lectura en voz alta de los estudiantes, en consonancia con lo planteado en otros estudios (Dueñas et al., 2014; Granado y Puig, 2015; Munita, 2013; Romero et al., 2015).

Como prospectivas, consideramos deseable trabajar en dos líneas: en primer lugar, extender este tipo de actividad al contexto de las prácticas en centros escolares, para seguir investigando cómo los estudiantes avanzan potenciando el saber teórico y el saber hacer en el contexto de la práctica profesional (Plazaola et al., 2018; Saiz-Linares y Ceballos-López, 2019). En segundo lugar, habida cuenta de que las obras que conforman el corpus de literatura infantil de reciente edición se sitúan, según el Observatorio de la Lectura y el Libro (España, Ministerio de Educación, Cultura y Deporte y Observatorio de la Lectura y el Libro, 2018), entre aquellas que gozan de mayor impacto comercial para primeros lectores o prelectores, resultaría muy interesante indagar sobre la influencia mediadora que ejerce el mercado editorial (Sánchez Hita y Romero, 2018).

\section{Referencias}

Amar, V. (2014). Didáctica y comunicación no verbal. Comunicación Social.

Ayuso, N. (2013). La literatura infantil como medio para enseñar valores [Trabajo de grado, Universidad de Valladolid]. http://uvadoc.uva.es/ handle/10324/3122 
Ballesteros, C., y Palou, J. (2005). Las creencias del profesorado y la enseñanza de la lengua oral. En M. Vilá, (Coord.), El discurso oral formal. Contenidos de aprendizaje y secuencias didácticas (pp. 101-116). Graó.

Birello, M., y Gil, M. (2014). Creencias sobre la enseñanza de la composición escrita y de la gramática de estudiantes de grado de Educación Primaria y de Educación infantil. Tejuelo, (10), 11-26. https:// dialnet.unirioja.es/descarga/articulo/5385983.pdf

Bolarín, M., y Moreno, M. (2015). La coordinación docente en la universidad: retos y problemas a partir de Bolonia. Profesorado. Revista de Curriculum y Formación del Profesorado, 19(2), 319-332. https://recyt.fecyt. es/index.php/profesorado/article/view/40928

Calonje, P. (2007). El sentido de leerles en voz alta. Educación y Biblioteca, año 19(157), 30-39. http://hdl. handle.net/10366/119330

Camps, A., y Vilá i Santasusana, M. (2003). Proyectos para aprender lengua. En A. Camps (Comp.), Secuencias didácticas para aprender a escribir (pp. 47-50). Graó.

Cassany, D. (2007). Luces y sombras de la lectura en voz alta. Peonza, (82), 21-32. https://handle/10230/21507

Cervera, J. (1989). En torno a la literatura infantil, Cauce: Revista de Filologíay su Didáctica, (12), 157-168. https:// dialnet.unirioja.es/servlet/articulo? codigo $=87702$

Chira, Y. (2018). Programa "más que historias" y su efectividad para la modificación de problemas conductuales en los niños del primer grado del nivel primario del Colegio Adventista del Titicaca - Chullunquiani, Juliaca, 2017 [Trabajo de grado, Universidad Peruana Unión]. http://repositorio.upeu.edu.pe/handle/UPEU/1439

Colomer, T., y Durán, T. (2000). La literatura en la etapa de educación infantil. En M. Correig y M. Bigas (Coord.), Didáctica de la lengua en educación infantil (pp. 213-250). Síntesis.

Díaz-Plaja, A. (2016). El diálogo entre los textos literarios. En M. Fons y J. Palou (Coords.), Didáctica de la lengua y la literatura en educación infantil (pp. 291300). Síntesis.

Dolz, J., y Schneuwly, B. (2016). Pour un enseignement de l'oral. Initiation aux genres formels a l'école. ESF.

Dueñas, J. D., Tabernero, R., Calvo, V., y Consejo, E. (2014). La lectura literaria ante nuevos retos: canon y mediación en la trayectoria lectora de futuros profesores. Ocnos, (11), 21-43. https://doi. org/10.18239/ocnos_2014.11.02

Duursma, E., Augustyn, M., y Zuckerman, B. (2008). Reading aloud to children: The evidence. Archives of
Disease in Childhood, 93(7), 554-557. https://doi. org/10.1136/adc.2006.106336

España, Ministerio de Educación, Cultura y Deporte y Observatorio de la Lectura y el Libro. (2018). Los libros infantiles y juveniles en España. https://issuu.com/gremideditorsdecatalunya/ docs/2018-los-libros-infantiles-y-juveni

Fandiño, L., Fiorellino, S., y Díaz, S. (2013). Voces que forman lectores. Una experiencia de trabajo con madres para la promoción de la lectura en voz alta en familia. En M. Núñez, J. Rienda y M. Santamarina (Coords.), Oralidad y educación (pp. 735-745). Monema.

Ferreiro, E. (Comp.) (2002). Relaciones de (in)dependencia entre oralidad y escritura. Gedisa.

Gatfield, T. (1999). Examining student satisfaction with group projects and peer assessment, Assessment \& Evaluation in Higher Education, 24(4), 365-377. https://doi.org/10.1080/0260293990240401

Gill, S. R. (2009). What teachers need to know about the "new" nonfiction. The Reading Teacher, 63(4), 260267. https://doi.org/10.1598/RT.63.4.1

Goikoetxea, E., y Martínez, N. (2015). Los beneficios de la lectura compartida de libros: breve revisión. Educación XX1, 18(1), 303-324. https://doi.org/10.5944/ educxx1.18.1.12334

Granado, C. (2013). La formación inicial de maestros y maestras en educación lectora: perspectiva del alumnado y contenidos ofrecidos en tres universidades andaluzas. Investigación en la escuela, 80, 103-115. http://hdl.handle.net/11441/51363

Granado, C., y Puig, M. (2014). ¿Qué leen los futuros maestros y maestras? Un estudio del docente como sujeto lector a través de los títulos de libros que evocan. Ocnos, (11), 93-112. https://doi.org/10.18239/ ocnos_2014.11.05

Granado, C., y Puig, M. (2015). La identidad lectora de los maestros en formación como componente de su identidad docente. Un estudio de sus autobiografías como lectores. Ocnos, (13), 43-63. https://doi. org/10.18239/ocnos_2015.13.03

Grau, M. y Vilá, M. (2005). La lectura en voz alta: enseñar a leer para comunicar. En M. Vilá (Coord.), El discurso oral formal. Contenidos de aprendizaje y secuencias didácticas (pp. 173-178). Graó.

Ibarra, M., Rodríguez, G. y Gómez, M. (2012). La evaluación entre iguales: beneficios y estrategias para su práctica en la Universidad. Revista de Educación, (359), 206-231. https://doi. org/10.4438/1988-592X-RE-2011-359-092 
Ibarra, N., y Ballester, J. (2013). La literatura infantil y juvenil en la formación del maestro. Lenguaje y Textos, (38), 11-18. http://www.sedll.org/sites/default/ files/journal/la_literatura_infantil_y_juvenil_en_ la_formacion_del_maestro._ibarra_n.pdf

Jarpa, M. (2019). Escritura académica para el desarrollo de la reflexión pedagógica en la formación docente: la crónica del docente-directivo. Íkala. Revista de Lenguaje y Cultura, 24(1), 85-101. https://doi.org/10.17533/ udea.ikala.v24n01a04

Juárez, M.a (2019). Influencia de la formación inicial del profesorado en los hábitos lectores y en el concepto de educación literaria. Investigaciones sobre lectura, (12), 99-131. https://doi.org/10.37132/isl.v0i12.287

Llamazares, M., y Alonso-Cortés, M. (2016). Lectura compartida y estrategias de comprensión lectora en educación infantil. Revista Iberoamericana de Educación, 71, 151-172. https://doi.org/10.35362/rie7109

Lomas, C. (2003). Leer para entender y transformar el mundo. Enunciación, 8(1), 57-67. https://revistas.udistrital. edu.co/index.php/enunc/article/view/2478

López-Pastor, V. M., y Pérez-Pueyo, Á. (Coords.). (2017). Evaluación formativa y compartida en educación: experiencias de éxito en todas las etapas educativas. Universidad de León.

Massaro,D.W.(2017). Readingaloud to children:Benefits and implications for acquiring literacy before schooling begins. American Journal of Psychology, 130(1), 6372. https://doi.org/10.5406/amerjpsyc.130.1.0063

Mata, J. (2004). El rastro de la voz y otras celebraciones de la lectura. Universidad de Granada.

Mata, J. (2016). Leer con otros. Aportaciones a la dimensión social de la lectura. RESED. Revista de Estudios Socioeducativos, (4), 16-26. http://hdl. handle.net/10498/18937

Mendoza, A. (2011). La investigación en didáctica de las primeras lenguas. Educatio Siglo XXI, 29(1), 31-80. https://revistas.um.es/educatio/article/view/119871

Montero, B. (2012). Bebecuentos. Esos grandes olvidados. CLIJ: Cuadernos de Literatura Infantil y Juvenil. (246), 30-34.

Moreno, A., y Sánchez Vera, L. (2000). Treinta años de la evolución de los estudios universitarios de literatura infantil en España: 1967-1997. En V. Ruzicka, C. Vázquez y L. Lorenzo (Eds.), Literatura infantil y juvenil. Tendencias actuales (pp. 85-95). Servicio de publicaciones de la Universidad de Vigo.

Moreno, A., y Sánchez Vera, L. (2006). El desarrollo de las habilidades lingüísticas en la educación infantil: literatura y tradición oral. En J. M. Serón (Ed.), La educación infantil: orientaciones y propuestas (pp. 397 447). Universidad de Cádiz.

Morón, E., y Martínez, C. (2013). La lectura en voz alta: una práctica necesaria para futuros maestros. En L. Cancelas, R. Jiménez, M. Romero y S. Sánchez (Coords.), Aportaciones para una educación lingüistica y literaria en el siglo XXI (pp. 1-7). Universidad de Cádiz.

Munita, F. (2013). Creencias y saberes de futuros maestros (lectores y no lectores) en torno a la educación literaria. Ocnos (9), 69-87. https://doi.org/10.18239/ ocnos_2013.09.04

Munita, F. (2019). "Volver a la lectura", o la importancia de la lectura personal en la formación continua del profesorado en didáctica de la lengua y la literatura. Profesorado. Revista de Currículum y Formación de Profesorado, 23(3), 413-430. https:// doi.org/10.30827/profesorado.v23i3.11236

Munita, F., y Riquelme, E. (2013). Leer con otros para leerse a sí mismo. La lectura mediada de literatura infantil y sus aportes en el desarrollo de las competencias emocionales del niño. A viva voz. Lectura en voz alta (pp. 30-45). Bibliotecas CRA/Mineduc.

New, R. S. (2001). Early literacy and developmentally appropriate practice: Rethinking the paradigm. En S. B. Neuman y D. K. Dickinson (Eds.), Handbook of early literacy research (vol. 1, pp. 245-262). Guilford Press.

Palou, J., y Bosch, C. (2005). La lengua oral en la escuela: 10 experiencias didácticas. Graó.

Parrado, M., Romero, M. F., y Trigo, E. (2018). La experiencia literaria en la formación de futuros docentes: el viaje iniciático de nuestras biografías en 10 hashtag. En V. Amar (Coord.), Miradas y voces de futuros maestros (pp. 59-86). Octaedro.

Pérez Peitx, M. (2016). El pensament sobre l'ensenyament i l'aprenentatge de la lectura i l'escriptura durant la formació inicial dels Mestres. Llengua, Societat i Comunicació, (14). https://revistes.ub.edu/index.php/ LSC/article/view/15382/19792

Planella, A. (2015). La formación del lector literario en la primera etapa de Educación Infantil [Trabajo de grado, Universidad Internacional de La Rioja]. https://reunir.unir.net/handle/123456789/3376

Plazaola, I., Ruiz, U., e Iriondo, I. (2018). Análisis de la propia actividad en el Practicum: una experiencia formativa. Revista Complutense de Educación, 29(4), 33-52. https://doi.org/10.5209/RCED.54890

Porta, L., y Silva, M. (2003). La investigación cualitativa: el análisis cualitativo en la investigación educativa. Anuario 
Digital de Investigación Educativa, (14), 388-406. http://revistas.bibdigital.uccor.edu.ar/index.php/ adiv/article/view/3211

Ribas, T. (2010). La evaluación en el área lingüística. Textos de Didáctica de la Lengua y de la Literatura, (53), 10-21.

Rodríguez, G., Ibarra, M., y Gómez, M. (2011). e-Autoevaluación en la universidad: un reto para profesores y estudiantes, Revista de Educación, (356), 401-430. https://doi. org/10.4438/1988-592X-RE-2011-356-045

Romero, M. F. (Coord.). (2011). La lectura expresiva en el aula. Propuesta de textos dialogados. Visión Libros.

Romero, M. F. (2016). La voz y la imagen de los cuentos en el imaginario colectivo desde la visión integradora del aula. En E. Álvarez, M. Martínez y L. Alejaldre (Coords.),Elcuento hispánico. Nuevas miradas criticas y aplicaciones didácticas (pp. 13-30). Agilice Digital.

Romero, M. F., Trigo, E., y Jiménez, R. (2015). Hojear la historia desde la educación literaria: un itinerario formativo para el joven lector. En R. Jiménez y M. F. Romero (Coords.), Nuevas lineas de investigación e innovación en la educación literaria (pp.109-119). Octaedro.

Romero, M. F., y Álvarez, E. (2018). El cuento en las biografías lectoras de los más jóvenes y sus historias completas. En E. Álvarez (Ed.), Acción y efecto de contar: estudios sobre el cuento hispánico contemporáneo (pp. 99-116). Visor.

Romero, M. F., y Trigo, E. (2014). Mira qué te cuento, la voz y la imagen de nuestras lecturas compartidas. En V. Amar (Coord.), Recuperary compartir la memoria de la escuela (pp. 15-25). GEU.

Romero, M. F., y Trigo, E. (2018). Entre las creencias y la formación inicial de los estudiantes del Máster de Profesorado de Secundaria: una mirada hacia la enseñanza de la literatura en las aulas. Profesorado. Revista de Curriculum y Formación del Profesorado, 22(1), 73-96. https://recyt. fecyt.es/index.php/profesorado/article/view/63622

Ruiz, M. (2019). La animación a la lectura: un camino para alcanzar el hábito y el placer por la lectura en la Educación Primaria [Trabajo de grado, Universidad de Valladolid]. http://uvadoc.uva.es/ handle/10324/39311

Sáez, J. (2017). Investigación educativa. Fundamentos teóricos, procesos y elementos prácticos (enfoque práctico con ejemplos. Esencial para TFG, TFM y tesis). UNED.

Saiz-Linares, A., y Ceballos-López, N. (2019). El practicum de magisterio a examen: reflexiones de un grupo de estudiantes de la Universidad de
Cantabria. Revista Iberoamericana de Educación Superior, 10(27), 136-150. https://doi.org/10.22201/ iisue.20072872e.2019.27.344

Sánchez Fernández, Y. (2014). El ambiente para la lectura literaria en Educación Infantil. Análisis de un contexto escolar [Trabajo de grado]. Universidad de Zaragoza.

Sánchez Hita, B., y Romero Oliva, M.F. (2018).Lecturas para los más jóvenes. Aproximación a la oferta editorial de literatura infantil para niños de 0-6 años. Tejuelo: Didáctica de la Lengua y la Literatura, (27), 149176. https://doi.org/10.17398/1988-8430.27.149

Sánchez Jiménez, M., y Galiano, A. (2019). Desarrollo de un equipo docente en la coordinación del profesorado en el ámbito universitario. Alteridad. Revista de Educación, 14(1), 98-108. https://doi. org/10.17163/alt.v14n1.2019.08

Sánchez Rodríguez, S. (2008). La asamblea de clase para la didáctica de la lengua oral en el segundo ciclo de educación infantil: estudio de casos. Santander [Tesis de doctorado] Universidad de Cantabria, España. http://hdl.handle.net/10902/1563

Sánchez Rodríguez, S. (2014). La alfabetización inicial en los últimos 25 años: de los métodos de lectura a las prácticas docentes para enseñar a leer y escribir. En M. F. Romero y R. Jiménez (Coords.), Hacia una educación lingüistica y literaria (pp. 177-198). UCA.

Sánchez Rodríguez, S. (2016). Hablar para comunicarse. En M. Fons y J. Palou (Coords.), Didáctica de la lengua y la literatura en educación infantil (pp. 165-178). Síntesis.

Santamarina, M. (2011). Análisis de las concepciones del profesorado de Educación Infantil sobre la enseñanza de la lengua oral: un estudio de caso. Enunciación, 16(2), 87-99. https://revistas.udistrital.edu.co/index.php/enunc/article/view/3907/14507

Santamarina, M. (2016). Análisis de las concepciones del profesorado de educación infantil sobre la enseñanza de la lengua oral: un estudio de casos. http://hdl.handle. net/10481/44299

Santamarina, M., y Núñez, M. (2018). Formación sobre didáctica de la lengua oral de los docentes de educación infantil españoles: un estudio comparativo. Profesorado. Revista de currículum y formación del profesorado, 22(1), 177-196. https://recyt.fecyt.es/ index.php/profesorado/article/view/63640/38698

Santana, R., Alemán, J., y López, M. (2017). Leer por placer ¡lo primero, oír los libros!, Aula abierta, 46(2), 83-90. https://doi.org/10.17811/ rifie.46.2.2017.83-90 
Santos Guerra, M. Á. (1993). La evaluación: un proceso de diálogo, comprensión y mejora. Investigación en la Escuela, (20), 23-35. http://hdl.handle. net/11441/59547

Soler, M. (2003). Lectura dialógica: la comunidad como entorno alfabetizador. En A. Teberosky y M. Soler (Comps.), Contextos de alfabetización inicial (pp. 47-63). ICE/Horsori.

Tolchinsky, L. (1990). Lo práctico, lo científico y lo literario: tres componentes en la noción de "alfabetismo". Comunicación, Lenguaje y Educación, 2(6), 53-62. https://doi.org/10.1080/02147033.1990.10820933

Trigo, E. (2016). El papel de la formación inicial y permanente del profesorado para forjar lectores. RESED, Revista de Estudios Socioeducativos, (4), 66-84. http://hdl.handle.net/10498/18941

Vicario, A. (2019). Literatura infantil y emoción: los cuentos infantiles de Trace Moroney como propuesta didáctica para el aula de primero de Educación Primaria [Trabajo de grado, Universidad de Cantabria]. http:// hdl.handle.net/10902/17705
Vilá, M. (Coord.). (2005). El discurso oral formal. Contenidos de aprendizaje y secuencias didácticas. Graó.

Wells, G. (2001). Indagación dialógica. Hacia una teoría y una práctica socioculturales de la educación. Paidós.

Wells, G. (2015). Dialogic learning: Talking our way into understanding. En T. Dragonas, K. J. Gergen, S. McNamee y E. Tseliou (Eds.), Education as social construction: Contributions to theory, research and practice (pp. 62-91). Taos Institute. https://www. researchgate.net/publication/280018440_Education_as_social_construction_Contributions_to_ theory_research_and_practice

Yoon, H., y Römer, U. (2020). Quantifying disciplinary voices: An automated approach to interactional metadiscourse in successful student writing. Written Communication, 37(2), 1-37. https://doi. org/ $10.1177 / 0741088319898672$

Young, T. A., Moss, B., y Cornwell, L. (2007), The classroom library: A place for nonfiction, nonfiction in its place. Reading Horizons, 48(1), 1-18. https://scholarworks. wmich.edu/reading_horizons/vol $48 /$ iss $1 / 3$

\section{Anexos}

Anexo 1. Corpus de obras seleccionadas

\begin{tabular}{|c|c|c|c|c|c|}
\hline Tí́tulo & Autor & Año & Editorial & Categoría & Frecuencia \\
\hline A qué sabe la luna & Michael Grejniec & 1999 & Kalandraka & $\mathrm{LI}$ & 5 \\
\hline Ada nunca tiene miedo & Isabel Córdova & 2002 & $\mathrm{sm}$ & $\mathrm{LI}$ & 1 \\
\hline Bonitas & Stacy McAnulty & 2018 & Astronave & lin & 1 \\
\hline Caperucita Roja & - & 2014 & Combel & $\mathrm{Cll}$ & 2 \\
\hline ¡Caray! Qué lista es mi madre & Ricardo Alcántara & 2002 & Combel & $\mathrm{ul}$ & 1 \\
\hline Carrera de zapatillas & Alejandra Bernardis & 2015 & Disponible en web* & LIN & 1 \\
\hline Carta va, carta viene & Alberto Urcaray & 2006 & Brosquil & $\mathrm{LI}$ & 1 \\
\hline ¿Cuándo llegará mi cumpleaños? & Alejandra Vallejo-Nágera & 2000 & Alfaguara & $\mathrm{LI}$ & 1 \\
\hline De qué están hechas las niñas flamencas & Montse Ganges & 2011 & Combel & LIN & 1 \\
\hline ¿Dónde estás oscuridad? & J. S. Pinillos & 2016 & Iajajai & LIN & 1 \\
\hline El erizo Pepe y sus globos de colores & - & - & Disponible en web** & $\mathrm{LI}$ & 1 \\
\hline El gallo Quirico & Tareixa Alonso & 2004 & Kalandraka & $\mathrm{ul}$ & 1 \\
\hline El gato con botas & Charles Perrault & 2009 & Timunmas & $\mathrm{CLI}$ & 2 \\
\hline El gran monstruo espantoso & Thomas Docherty & 2010 & Anaya & $\mathrm{LI}$ & 1 \\
\hline El hada acatarrada & Miguel Ángel Mendo & 1996 & Bruño & u & 1 \\
\hline El libro inquieto & Los Krickelkrakels & 2012 & Kokinos & u & 1 \\
\hline El libro sin dibujos & B. J. Novak & 2015 & Timunmas & $\mathrm{LI}$ & 1 \\
\hline El milagro del oso & Wolf Erlbruch & 2002 & Lóguez & $\mathrm{LI}$ & 1 \\
\hline El monstruo de los colores & Anna Llenas & 2012 & Flamboyant & LIN & 1 \\
\hline
\end{tabular}


Anexo 1. Corpus de obras seleccionadas (continuación)

\begin{tabular}{|c|c|c|c|c|c|}
\hline Título & Autor & Año & Editorial & Categoría & Frecuencia \\
\hline El monstruo rosa & Olga De Dios & 2013 & Apila & LIN & 1 \\
\hline El oso, la mona y el cerdo & Tomás de Iriarte & 2018 & Disponible en web ${ }^{* * * *}$ & $\mathrm{Cll}$ & 1 \\
\hline El palacio del pájaro azul & Orianne Lallemand & 2012 & Edelvives & $\mathrm{LI}$ & 1 \\
\hline El pastor mentiroso & Félix María de Samaniego & 2004 & Combel & $\mathrm{CLI}$ & 1 \\
\hline El patito feo & Hans Christian Andersen & 2006 & Combel & $\mathrm{Cll}$ & 1 \\
\hline El perro de color melón & $\begin{array}{l}\text { Asociación para el bienestar } \\
\text { de los animales }\end{array}$ & 2012 & $\begin{array}{l}\text { Defensor del menor. } \\
\text { Comunidad de Madrid }\end{array}$ & LIN & 1 \\
\hline El perro picatoste & Gloria Fuertes & 2014 & Susaeta & LI & 1 \\
\hline El pez arcoíris & Marcus Pfister & 2013 & Beascoa & $\mathrm{LI}$ & 3 \\
\hline El príncipe feliz & Oscar Wilde & 2015 & SM & $\mathrm{ClI}$ & 1 \\
\hline El principito & Antoine de Saint-Exupéry & 2008 & Salamandra & $\mathrm{Cll}$ & 1 \\
\hline El retorno de Villarina & W. AA. & 2010 & Fapas & $\mathrm{LI}$ & 1 \\
\hline El sueño de Matías & Leo Lionni & 2013 & Kalandraka & $\mathrm{LI}$ & 1 \\
\hline $\begin{array}{l}\text { El topo que quería saber quién se había } \\
\text { hecho aquello en su cabeza }\end{array}$ & Werner Holzwarth & 2015 & Beascoa & $\mathrm{LI}$ & 1 \\
\hline El zorro y el caballo & Hermanos Grimm & 2010 & Artemisa & $\mathrm{ClI}$ & 2 \\
\hline Elmer & David McKee & 2012 & Beascoa & $\mathrm{LI}$ & 2 \\
\hline Embrujo en la granja & Eulália Abad Roca & 2017 & Bellaterra Música & LIN & 1 \\
\hline En la selva & VV. AA. & 2014 & - & LIN & 1 \\
\hline ¡Este pijama está loco! & Andrés Guerrero & 1991 & Anaya & $\mathrm{LI}$ & 1 \\
\hline Fonchito y la luna & Mario Vargas Llosa & 2015 & Alfaguara & $\mathrm{ul}$ & 1 \\
\hline Frederick & Leo Lionni & 2005 & Kalandraka & LI & 1 \\
\hline Garbancito & Olalla González & 2008 & Kalandraka & $\mathrm{LI}$ & 1 \\
\hline Hansel y Gretel & Hermanos Grimm & 2016 & Combel & $\mathrm{Cll}$ & 1 \\
\hline Juan y las habichuelas mágicas & Hans Christian Andersen & 2006 & Bruño & $\mathrm{CLI}$ & 1 \\
\hline La casita de chocolate & Hermanos Grimm & 2013 & Kalandraka & $\mathrm{Cll}$ & 1 \\
\hline La cenicienta & Charles Perrault & 2013 & Timunmas & $\mathrm{CLI}$ & 1 \\
\hline La cigarra y la hormiga & Esopo & 2010 & Laberinto & $\mathrm{CLI}$ & 1 \\
\hline La invitación de cumpleaños & Lucy Rowland & 2017 & Picarona & $\mathrm{LI}$ & 1 \\
\hline La pequeña oruga glotona & Eric Carle & 2017 & Kókinos & $\mathrm{ul}$ & 2 \\
\hline La ratita presumida & Charles Perrault & 2017 & Combel & $\mathrm{CLI}$ & 2 \\
\hline La sirenita & Hans Christian Andersen & 2015 & Timunmas & $\mathrm{CLI}$ & 1 \\
\hline La tortuga poco a poco & David Paloma & 2000 & Combel & $\mathrm{LI}$ & 1 \\
\hline La tortuga que quería dormir & Roberto Aliaga & 2008 & oqo & $\mathrm{LI}$ & 1 \\
\hline La vaca que puso un huevo & Andy Cutbill & 2008 & Serres & $\mathrm{ul}$ & 3 \\
\hline Las cuatro estaciones en un día & Katie Cotton & 2016 & Bruño & LIN & 1 \\
\hline Las jirafas no pueden bailar & Giles Andreae & 2014 & Bruño & $\mathrm{ul}$ & 1 \\
\hline Las piezas del puzle & Babette Cole & 2007 & rba & $\mathrm{LI}$ & 1 \\
\hline Lina sale en el periódico & Elisa Mariscal & 2002 & Santillana & LIN & 1 \\
\hline Los tres cerditos & - & $2014 / 2018$ & Combel/Timunmas & $\mathrm{CLI}$ & 2 \\
\hline María y el niño envidioso & Manfred Sommer Resalt & 2002 & Everest & $\mathrm{LI}$ & 1 \\
\hline
\end{tabular}


Anexo 1. Corpus de obras seleccionadas (continuación)

\begin{tabular}{|c|c|c|c|c|c|}
\hline Tí́tulo & Autor & Año & Editorial & Categoría & Frecuencio \\
\hline Mecachis, iquiero ser grande! & Ricardo Alcántara & 2016 & Combel & $\mathrm{LI}$ & 1 \\
\hline No eres una lagartija & Concha López Narváez & 1996 & Anaya & $\mathrm{LI}$ & 1 \\
\hline Olivia y la carta a los Reyes Magos & Elvira Lindo & 2005 & $\mathrm{sm}$ & LI & 1 \\
\hline Pepa aprende a compartir & María Mañerú & 2018 & Libsa & LIN & 1 \\
\hline Perico el conejo travieso & Beatrix Potter & 1993 & Debate & LI & 2 \\
\hline Pinocho & Carlo Collodi & 2015 & San Pablo & $\mathrm{Cll}$ & 1 \\
\hline Pollito Pito & Josefina Urdaneta & 2000 & Playco & $\mathrm{LI}$ & 1 \\
\hline ¿Quién es? ¡Cuidado! & Patricia Hegarty & 2015 & Combel & $\mathrm{LI}$ & 1 \\
\hline Ricitos de oro & - & 2016 & Combel & $\mathrm{LI}$ & 1 \\
\hline Rodolfo y la mueca & Tony Ross & 1991 & Altea & LI & 1 \\
\hline Siempre te querré, pequeñín & Debi Gliori & 2005 & Planeta & $\mathrm{LI}$ & 1 \\
\hline Sueños de volar & Teresa Marques & 2016 & Kalandraka & $\mathrm{LI}$ & 1 \\
\hline Te quiero (casi siempre) & Anna Llenas & 2015 & Espasa & $\mathrm{LI}$ & 1 \\
\hline Te quiero ratoncita & Dugald Steer & 2004 & Alfaguara & LI & 1 \\
\hline Teo y su cumpleaños & Violeta Denou & 1992 & Timunmas & LIN & 1 \\
\hline Teo y su familia & Violeta Denou & 1992 & Timunmas & LIN & 1 \\
\hline Tito busca nariz & Guido van Genechten & 2002 & Edelvives & LI & 1 \\
\hline Toño se queda solo & Thierry Lenain & 2002 & Edelvives & $\mathrm{LI}$ & 1 \\
\hline Topito terremoto & Anna Llenas & 2017 & Beascoa & LIN & 1 \\
\hline Un bicho extraño & Mon Daporta & 2009 & Kalandraka & LI & 1 \\
\hline Un culete independiente & José Luis Cortés & 2005 & $\mathrm{sm}$ & $\mathrm{LI}$ & 1 \\
\hline Veo veo ¿Un ratón? & Guido Van Genechten & 2003 & Edelvives & $\mathrm{LI}$ & 1 \\
\hline Yo mataré monstruos por ti & Santi Balmes & 2017 & Principal & $\mathrm{LI}$ & 2 \\
\hline
\end{tabular}

CLI: Clásicos de literatura infantil; li: Literatura infantil; lin: Literatura instrumentalizada

${ }^{*}$ Guiainfantil.com. Cuento infantil. Carrera de zapatillas. https://www.guiainfantil.com/1210/cuento-infantil-carrerade-zapatillas.html

${ }^{* *}$ https://es.scribd.com/document/409054836/El-Erizo-Pepe-y-Sus-Globos-de-Colores

*** Esteban, E. (2018). El oso, la mona y el cerdo. Fábula de Iriarte para niños. https://www.guiainfantil.com/articulos/ ocio/fabulas/el-oso-la-mona-y-el-cerdo-fabula-de-iriarte-para-ninos/ 


\section{Anexo 2. Modelo de rúbrica utilizada en las fases II y III}

\begin{tabular}{l|l}
\hline \multicolumn{1}{c}{ Recursos paralingiísticos } & \multicolumn{1}{c}{ Recursos que acompañan la narración } \\
\hline Voz flexible. El narrador posee una voz flexible que le permite modularla de cualquier & \multicolumn{1}{c}{ Valón } \\
forma para interpretar, diferenciar y dar vida a los distintos personajes que interpreta o & \\
para la reproducción de las onomatopeyas empleadas en la narración & \\
La entonación. El narrador posee una entonación que sirve para determinar los estados & \\
de ánimo de los personajes que intervienen en la narración & \\
Las pausas y los silencios. El narrador emplea pausas y silencios que sirven para atraer & \\
la atención y crear suspenso & Valoración \\
Dicción y modulación. El narrador posee una buena dicción y modulación que contribuye & \\
a un relato claro y comprensible, que se puede gozar y disfrutar & \multicolumn{1}{c}{ Recursos no verbales } \\
\hline
\end{tabular}

Anexo 3. Modelo de rúbrica utilizada en las fases v y vi

\begin{tabular}{|c|c|c|c|c|c|c|c|}
\hline & & & & Mejorable & Adecuado & Destacado & Excelente \\
\hline \multirow{9}{*}{$\begin{array}{l}\text { Lenguaje } \\
\text { verbal }\end{array}$} & Prosódicos & Entonación & $\begin{array}{l}\text { Habla según el estado de ánimo de los } \\
\text { personajes, se identifica cuando es una } \\
\text { interrogación y cuando es una exclamación }\end{array}$ & & & & \\
\hline & \multirow{7}{*}{ Paralingiósticos } & Modulación & $\begin{array}{l}\text { Cambia la voz de grave a agudo y } \\
\text { viceversa, según corresponda. También de } \\
\text { alto a bajo, y viceversa }\end{array}$ & & & & \\
\hline & & \multirow{4}{*}{ Dicción } & $\begin{array}{l}\text { Nitidez y claridad en el uso de las } \\
\text { palabras, de manera que se comprenda de } \\
\text { forma clara lo que se quiere expresar }\end{array}$ & & & & \\
\hline & & & $\begin{array}{l}\text { La intensidad o volumen es adecuado al } \\
\text { contexto (número de alumnos, disposición } \\
\text { del aula, etc.) }\end{array}$ & & & & \\
\hline & & & $\begin{array}{l}\text { Lee de forma tranquila (no lenta). } \\
\text { Articulación y vocalización correcta de las } \\
\text { palabras }\end{array}$ & & & & \\
\hline & & & Lee respetando un ritmo adecuado al texto & & & & \\
\hline & & Voz flexible & $\begin{array}{l}\text { Diferencia los personajes, uso de } \\
\text { onomatopeyas acompañadas de gestos }\end{array}$ & & & & \\
\hline & & $\begin{array}{l}\text { Pausas y } \\
\text { silencios }\end{array}$ & $\begin{array}{l}\text { Respeta las comas y los puntos, utiliza } \\
\text { una voz no "ahogada" (cuidado en la } \\
\text { respiración) }\end{array}$ & & & & \\
\hline & Observaciones & & & & & & \\
\hline
\end{tabular}


Anexo 3. Modelo de rúbrica utilizada en las fases v y vi (Continuación)

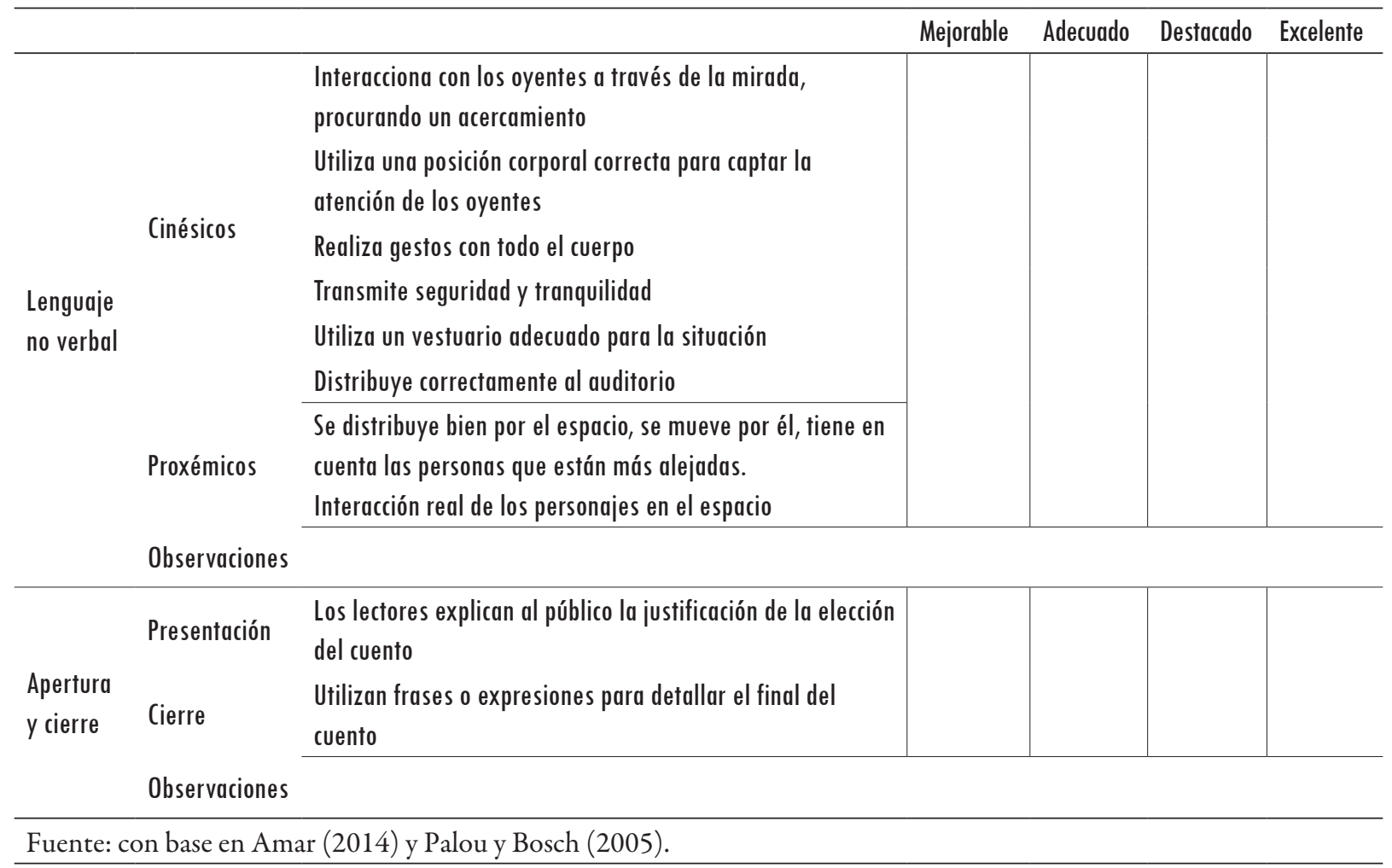

Cómo citar este artículo: Trigo-Ibáñez, E., Rivera-Jurado, P., y Sánchez-Rodríguez, S. (2020). La lectura en voz alta en la formación inicial de los maestros de educación infantil de la Universidad de Cádiz. Íkala, Revista de Lenguaje y Cultura, 25(3), 605-624. https:/doi.org/10.17533/udea.ikala.v25n03a07 